\title{
Effect of Coadministered Lopinavir/Ritonavir and Sulfamethoxazole/Trimethoprim on Liver Function and Achitecture of Albino Rats
}

\author{
Adikwu Elias $^{1, *}$, Deo Oputiri ${ }^{2}$, Oru-Bo Precious Geoffrey ${ }^{2}$ \\ ${ }^{1}$ Department of Pharmacology, Faculty of Basic Medical Sciences, College of Health Sciences, University of Port Harcourt, Choba, \\ Rivers State, Nigeria \\ ${ }^{2}$ Department of Pharm Tech, College of Health Technology, Otuogidi, Ogbia, L. G. A., Bayelsa State \\ *Corresponding author: adikwuelias@gmail.com
}

Received July 31, 2014; Revised August 16, 2014; Accepted August 27, 2014

\begin{abstract}
HIV/AIDS is usually associated with co morbidities and co infections which may necessitate the concurrent use of antiretroviral drugs with other medications. This may place more burdens on body organs especially the liver which is the primary organ of drug metabolism. Therefore this study evaluates the toxicological effect of single and combined doses of SMX/TMP + LPV/r on the liver function and architecture of rats. Seventy five (75) animals which were divided into five (5) groups were used in this study. Group A which served as control contained fifteen (15) animals which were treated with $1 \%$ ethanol orally. Group B-E which contained fifteen (15) animals each was further subdivided into three (3) subgroups of five (5) animals each. Animals in these groups were treated with oral doses of SMX/TMP (11.2/2.3mg/kg), LPV/r (11.4/2.9mg/kg) and combine doses of SMX/TMP + $\mathrm{LPV} / \mathrm{r}$ for 2-8 weeks respectively. Plasma levels of alanine aminotranferase, (ALT) aspartate aminotranferase, (ALT), and alkaline phosphatase (ALP) were evaluated. Liver malondialdehyde, superoxide dismutase and histopathological changes were also evaluated. Results showed that these agents have no significant toxic effects on the liver weight. Treatment with single doses of SMX/TMP and LPV/r produced a time dependent increase in AST, ALT, ALP and MDA. Significant synergistic increases in these parameters were not observed when these agents $(\mathrm{SMX} / \mathrm{TMP}+\mathrm{LPV} / \mathrm{r})$ were co administered. Single doses of these agents produced a time dependent decrease in SOD with no significant synergistic effects when combined doses of these agents (SMX/TMP + LPV/r) were used. Liver of animals treated with single and combined doses of SMX/TMP and LPV/r showed fairly preserved lobular architecture with vascular congestion and inflammatory cells infiltration in the parenchyma. Conclusion: In this study concurrent treatment with SMX/TMP + LPV/r produced no synergistic hepatotoxicity, hence these agents can be use concurrently in HIV/AIDS associated co infection and co morbidity.
\end{abstract}

Keywords: liver, toxicity, sulfamethoxazole/trimethoprim, lopinavir/ritonavir, rats

Cite This Article: Adikwu Elias, Deo Oputiri, and Oru-Bo Precious Geoffrey, "Effect of Coadministered Lopinavir/Ritonavir and Sulfamethoxazole/Trimethoprim on Liver Function and Achitecture of Albino Rats." American Journal of Pharmacological Sciences, vol. 2, no. 4 (2014): 65-71. doi: 10.12691/ajps-2-4-2.

\section{Introduction}

Human immunodeficiency virus scourge is a global problem; the Joint United Nations Program on HIV/AIDS estimated that 29.4 Million Africans are infected with HIV [1]. UNAIDS 2012 reported a global, estimation of people living with HIV/AID as 35.3 (32.2-38.8) million people with 2.3 (1.9-2.7) million new infections [2]. There is increasing evidence that HIV epidemic is in decline among general population worldwide probably due to awareness and the availability of highly active antiretroviral therapy [3]. Lopinavir boosted with ritonavir (LPV/r) is among the currently used antiretroviral drugs. Lopinavir is boosted with ritonavir because lopinavir is easily metabolized by hepatic CYP3A4 and CYP3A5 hence ritonavir inhibits the CYP3A4 isoenzymes and results in increase concentration of lopinavir when co formulated. This formulation provides a lower pill burden, similar bioavailability, decreased effect of food on absorption of the drug, and an elimination of the refrigeration requirement. Despite these clinical benefits $\mathrm{LPV} / \mathrm{r}$ is reported to be associated with elevated levels of transaminases which could increase severe risk of liver events [4].

Sulfamethoxazole/ trimethoprim is a fixed dose combination drug (SMX/TMP) that has a broad spectrum of action against microorganisms. This combination inhibits the synthesis of metabolically active form of folic acid and tetrahydrofolic acid in microorganisms. Despite the therapeutic benefits and therapeutic success achieved with the use of SMX/TMP, scholars have associated it with hepatotoxicity which is characterized by elevations in transaminases [5]. Due to co infections and co morbidity 
associated with HIV/AIDS, WHO recommends sulphamethoxazole/trimethoprim (SMX/TMP) preventive therapy for people living with HIV/AIDS in Africa with symptomatic HIV diseases and asymptomatic individuals who have a CD4 count of less than or equal to 500 cells/mm3 [6]. The presence of co infections and co morbidities among people living with HIV may involve the concurrent use of antiretroviral agents with other medications which permits the concurrent use of SMX/TMP and LPV/r. Because these drugs are associated with hepatic adverse events the concurrent use of these drugs may add more toxicological burden on the liver which could be of clinical concern. The liver is known as the second largest organ in the body and is a custodian of myriads of functions. These functions include detoxification, synthesis of clotting factors, metabolism of lipids and carbohydrates [7]. It is also a major organ involved in digestive activities within the digestive system. Substantial disruption in its anatomy or function may result in severe alteration in its metabolic roles, and this may adversely affect physiological functions [8]. Therefore this study investigates the toxicological effects of the co administration of lopinavir/ritonavir and sulfamethoxazole/trimethoprim on liver function and architecture of rats.

\section{Materials and Methods}

\subsection{Drugs}

Lopinavir/ritonavir (LPV/r) used in this work was manufactured by Myland Laboratories Limited India. Other ingredients in the LPV/r tablet include colloidal silicon dioxide, copovidone, sodium stearyl fumarate and sorbitan monolaurate. Sulfamethoxazole/Trimethoprim (SMX/TMP) used in this study was manufactured by CSPC Ouyi Pharmaceuticals China. Other ingredients in SMX/TMP tablets include docusate sodium, magnesium stearate, maize starch, silica and sodium lauryl sulphate.

\subsection{Animals}

The animals used in this research work were obtained from the animal house of the Department of Pharmacology and Toxicology, Madonna University, Elele, Rivers State. The animals were allowed free access to food and water ad libitum and were allowed to acclimatize for 14 days. Animals were handled according to Helsinki declaration on the handling and use of animals.

\subsection{Dose Selection}

$11.2 / 2.3 \mathrm{mg} / \mathrm{kg}$ of SMX-TMP and $11.4 / 2.9 \mathrm{mg} / \mathrm{kg}$ of $\mathrm{LPV} / \mathrm{r}$ were used in this study. Doses used are within the clinically recommended dose range $[9,10]$.

\subsection{Preparation of Drug}

Lopinavir/ritonavir tablets were crushed and dissolved in $1 \%$ ethanol while Sulphamethoxazole/ trimethoprim tablets were crushed and dissolved in sterile water [11].

\subsection{Grouping of Animals}

Seventy five healthy male rats were weighed and housed in a large mesh cage. The rats were divided into five groups A B C D and E.

\subsection{Drug Administration}

Group A: This served as the control and contained fifteen animals which were treated with $1 \%$ ethanol orally throughout the duration of study.

Group B: This group contained 15 animals which were further divided into three subgroups (B1-B3) of 5animals each. Animals in sub group B1 were treated with $11.2 / 2.3 \mathrm{mg} / \mathrm{kg}$ of SMX/TMP. Animals in subgroup B2 were treated with $11.4 / 2.9 \mathrm{mg} / \mathrm{kg}$ of $\mathrm{LPV} / \mathrm{r}$. Animals in subgroup B3 were treated with combined doses of SMX/TMP + LPV/r. All animals in this group were treated for 2 weeks

Group C: This group contained 15 animals which were further divided into three subgroups (C1-C3) of 5 animals each. Animals in sub group $\mathrm{C} 1$ were treated with $11.2 / 2.3 \mathrm{mg} / \mathrm{kg}$ of SMX/TMP. Animals in subgroup C2 were treated with $11.4 / 2.9 \mathrm{mg} / \mathrm{kg}$ of LPV/r. Animals in C3 were treated with combined doses of SMX/TMP + LPV/r. All animals in this group were treated for 4 weeks

Group D: This group contained 15 rats which were further divided into three subgroups (D1-D3) of 5 animals each. Animals in sub group D1 were treated with $11.2 / 2.3 \mathrm{mg} / \mathrm{kg}$ of SMX/TMP. Animals in subgroup D2 were treated with $11.4 / 2.9 \mathrm{mg} / \mathrm{kg}$ of LPV/r. Animals in D3 were treated with combined doses of SMX/TMP + LPV/r. All animals in this group were treated for 6 weeks.

Group E: This group contained 15 animals which were further divided into three subgroups (E1-E3) of 5 animals each. Animals in sub group E1 were treated with $11.2 / 2.3 \mathrm{mg} / \mathrm{kg}$ of SMX/TMP. Animals in subgroup E2 were treated with $11.4 / 2.9 \mathrm{mg} / \mathrm{kg}$ of LPV/r. Animals in E3 were treated with combined doses of SMX/TMP + LPV/r. All animals in this group were treated for 8 weeks

\subsection{Collection of Sample for Analysis}

Animals were sacrificed using chloroform anesthesia at the end of 2, 4, 6 and 8 weeks of treatment respectively. Blood sample was collected from the common carotid artery. The sample was allowed to clot and centrifuged at 1000 rpm for 5mins using Uniscope centrifuge and serum separated for analysis. Rats were dissected liver was collected, weighed and analyzed for histopathological changes.

\subsection{Preparation of Tissue Homogenate}

The liver tissues were homogenized using $0.1 \%$ Triton $\mathrm{X}-100$ buffer ( $\mathrm{pH} 7.4$ ). The homogenate was centrifuged at $12,000 \mathrm{rpm} \&$ at $4^{\circ} \mathrm{C}$ for $30 \mathrm{~min}$ and the supernatant was used as sample for biochemical investigations [12]

\subsection{Evaluation of Liver Malondialdehyde and Superoxide Dismutase}

The liver malondialdehyde (MDA) and superoxide dismutase (SOD) were determined according to Draper and Hadley [13], Beauchamp and Fridovic [14], respectively. 


\subsection{Evaluation of Serum Liver Function Parameters}

Estimation of aspartate aminotransdferase (AST) activities and alanine aminotransferase (ALT) activities were done using Reitman-Frankel method [15]. Estimation of alkaline phosphatase was performed using King and King Method [16]. Total bilirubin was determined using Malloy and Evelyn method [17].

\subsection{Histopathological Evaluation}

For light microscopic examination, liver tissues from each group were fixed with $10 \%$ buffered formalin. The specimens were dehydrated in ascending grades of ethanol, cleared in xylene and embedded in paraffin wax. Sections of $5 \mathrm{~cm}$ in thickness were prepared and stained with Haematoxylin and Eosin [18] and then examined under light microscopy. The photomicrographs of the relevant stained sections were taken with the aid of a light microscope.

\subsection{Statistical Analysis}

Results were expressed as mean \pm S.E.M. Statistical analysis was done with the aid of SPSS for windows; SPSS Inc., Chicago, Standard version 14.0 to determine difference between mean using One Way Analysis of Variance (ANOVA).

\section{Results}

\subsection{Effects on Liver Weight, AST, ALT, and ALP}

Table 1. Effect of lopinavir/ritonavir, sulfamethoxazole/ trimethoprim and co-administered lopinavir/ritonavir + sulfamethoxazole/trimethoprim on liver weight (gram) in rats

\begin{tabular}{|lllll|}
\hline Dose $\mathrm{mg} / \mathrm{kg}$ & Week2 & Week4 & Week 6 & Week 8 \\
\hline
\end{tabular}

\begin{tabular}{|lllll|}
\hline Control & $2.73 \pm 0.13$ & $2.81 \pm 2.04$ & $2.63 \pm 0.15$ & $2.75 \pm 3.13$ \\
\hline
\end{tabular}

\begin{tabular}{|lllll|}
\hline SMX/TMP (11.2/2.3) & $2.58 \pm 0.24$ & $2.92 \pm 0.53$ & $2.76 \pm 0.14$ & $2.74 \pm 0.04$
\end{tabular}

\begin{tabular}{llllll|}
\hline LPV/r (11.4/2.9) & $2.52 \pm 0.30$ & $2.20 \pm 0.15$ & $2.87 \pm 0.02$ & $2.69 \pm 0.23$ \\
\hline
\end{tabular}

\begin{tabular}{lllll|}
\hline SMX/TMP+LPV/r & $2.35 \pm 0.1$ & $2.17 \pm 0.03$ & $2.41 \pm 0.28$ & $2.61 \pm 0.28$ \\
\hline
\end{tabular}

Results are expressed as mean \pm SEM, the superscript $\left({ }^{*}\right)$ means

significant difference with respect to the control at $\mathrm{p}<0.05$ (ANOVA).

Table 2. Effect of lopinavir/ritonavir, sulfamethoxazole/ trimethoprim and co-administered lopinavir/ritonavir + sulfamethoxazole/trimethoprim on serum AST (U/L) in rats

\begin{tabular}{|ccccc|}
\hline Dose mg/kg & Week2 & Week4 & Week 6 & Week 8 \\
\hline Control & $20.1 \pm 1.41$ & $21.2 \pm 2.42$ & $22.4 \pm 0.31$ & $22.7 \pm 0.42$ \\
\hline $\begin{array}{c}\text { SMX/TMP } \\
(\mathbf{1 1 . 2} / \mathbf{2 . 3 )}\end{array}$ & $21.5 \pm 0.65$ & $22.0 \pm 0.41$ & $30.5 \pm 0.48^{*}$ & $34.5 \pm 0.65^{*}$ \\
\hline $\begin{array}{c}\text { LPV/r } \\
(\mathbf{1 1 . 4} / \mathbf{2 . 9})\end{array}$ & $22.5 \pm 0.45$ & $22.7 \pm 0.75$ & $34.2 \pm 0.38^{*}$ & $36.7 \pm 0.48^{*}$ \\
\hline SMX/TMP+LPV/r & $22.2 \pm 0.63$ & $24.2 \pm 0.48$ & $45.5 \pm 0.80^{*}$ & $47.1 \pm 0.71^{*}$ \\
\hline
\end{tabular}

Results are expressed as mean \pm SEM, the superscript (*) means

significant difference with respect to the control at $\mathrm{p}<0.05$ (ANOVA).

The effects of SMX/TMP, LPV/r and SMX/TMP +

$\mathrm{LPV} / \mathrm{r}$ on liver weight, serum AST, and ALT are shown in Table 1-Table 4. This result shows that SMX/TMP, LPV/r and combined doses of SMX/TMP $+\mathrm{LPV} / \mathrm{r}$ did not produce any significant change in the liver weight after treatment for 2- 8 weeks with respect to the control. [Table 1] Treatment with SMX/TMP, LPV/r produced significant $(\mathrm{p}<0.05)$ increase in AST, in week 6 and 8 with respect to the control. Also significant increase $(\mathrm{p}<0.05)$ in AST was noted in animals co administered SMX/TMP $+\mathrm{LPV} / \mathrm{r}$ in week 6 and week 8 respectively when compared with the control. [Table 2] Treatment with single doses of SMX/TMP, LPV/r produced significant $(\mathrm{p}<0.05)$ increase in ALT, in week 6 and 8 with respect to the control. Elevation in the level of ALT was significantly $(\mathrm{p}<0.05)$ observed when animals were treated with combined doses of SMX/TMP + LPV/r for 6 and 8 weeks with respect to the control. [Table 3] Animals treated with separate doses of $\mathrm{LPV} / \mathrm{r}$ and SMX/TMP produced time dependent increase in ALP which was significant in week 6 and 8 while combined doses of these agents $\mathrm{LPV} / \mathrm{r}+\mathrm{SMX} / \mathrm{TMP}$ also produced significant increase in week 4-8 when compared with the control [Table 4].

Table 3. Effect of lopinavir/ritonavir, sulfamethoxazole/ trimethoprim and co-administered lopinavir/ritonavir + sulfamethoxazole/trimethoprim on serum ALT (U/L) in rats

\begin{tabular}{|lcccc|}
\hline Dose mg/kg & Week2 & Week4 & Week 6 & Week 8 \\
\hline Control & $20.5 \pm 1.25$ & $21.2 \pm 2.35$ & $22.0 \pm 0.47$ & $22.4 \pm 3.15$ \\
\hline $\begin{array}{l}\text { SMX/TMP } \\
(\mathbf{1 1 . 2} / 2.3)\end{array}$ & $20.5 \pm 2.29$ & $23.0 \pm 3.41$ & $31.0 \pm 1.41^{*}$ & $35.5 \pm 1.19^{*}$ \\
\hline $\begin{array}{l}\text { LPV/r } \\
(\mathbf{1 1 . 4 / 2 . 9 )}\end{array}$ & $21.0 \pm 1.41$ & $24.2 \pm 2.48$ & $35.0 \pm 2.85^{*}$ & $37.7 \pm 1.11^{*}$ \\
\hline SMX/TMP+LPV/r & $22.5 \pm 0.48$ & $25.5 \pm 1.15$ & $40.5 \pm 0.65^{*}$ & $44.0 \pm 3.71^{*}$ \\
\hline
\end{tabular}

SMX/TMP+LPV/r $\quad 22.5 \pm 0.48 \quad 25.5 \pm 1.15 \quad 40.5 \pm 0.65 * \quad 44.0 \pm 3.71 *$ Results are expressed as mean \pm SEM, the superscript (*) means significant difference with respect to the control at $\mathrm{p}<0.05$ (ANOVA).

Table 4. Effect of lopinavir/ritonavir, sulfamethoxazole/ trimethoprim and co-administered lopinavir/ritonavir + sulfamethoxazole/ trimethoprim on serum ALP (U/L) in rats

\begin{tabular}{|ccccc|}
\hline Dose mg/kg & Week2 & Week4 & Week 6 & Week 8 \\
\hline Control & $19.2 \pm 2.73$ & $21.2 \pm 3.41$ & $21.4 \pm 1.85$ & $21.6 \pm 3.15$ \\
\hline $\begin{array}{c}\text { SMX/TMP } \\
(\mathbf{1 1 . 2 / 2 . 3 )}\end{array}$ & $21.2 \pm 2.75$ & $23.0 \pm 3.41$ & $31.2 \pm 3.48^{*}$ & $33.5 \pm 1.71^{*}$ \\
\hline $\begin{array}{c}\text { LPV/r } \\
(\mathbf{1 1 . 4 / 2 . 9 )}\end{array}$ & $21.2 \pm 1.63$ & $25.0 \pm 0.91$ & $34.7 \pm 1.44^{*}$ & $37.5 \pm 1.32^{*}$ \\
\hline SMX/TMP+LPV/r & $23.0 \pm 1.29$ & $35.7 \pm 1.75^{*}$ & $40.7 \pm 1.03^{*}$ & $42.7 \pm 0.48^{*}$ \\
\hline
\end{tabular}

Results are expressed as mean \pm SEM, the superscript $\left(^{*}\right)$ means significant difference with respect to the control at $\mathrm{p}<0.05$ (ANOVA).

Table 5. Effect of lopinavir/ritonavir, sulfamethoxazole/ trimethoprim and co-administered lopinavir/ritonavir, + sulfamethoxazole/trimethoprim on liver MDA (nmole/g tissue) in rats

\begin{tabular}{|lcccc|}
\hline Dose mg/kg & Week2 & Week4 & Week 6 & Week 8 \\
\hline Control & $22.3 \pm 0.05$ & $23.5 \pm 1.23$ & $23.9 \pm 1.26$ & $24.2 \pm 3.22$ \\
\hline $\begin{array}{l}\text { SMX/TMP } \\
(\mathbf{1 1 . 2 / 2 . 3 )}\end{array}$ & $24.0 \pm 2.15$ & $25.3 \pm 0.23$ & $41.0 \pm 2.17^{*}$ & $42.5 \pm 1.36^{*}$ \\
\hline $\begin{array}{l}\text { LPV/r } \\
(\mathbf{1 1 . 4 / 2 . 9 )}\end{array}$ & $26.0 \pm 3.16$ & $28.8 \pm 2.23$ & $44.0 \pm 1.24^{*}$ & $45.5 \pm 3.16^{*}$ \\
\hline SMX/TMP+LPV/r & $28.0 \pm 3.04$ & $29.5 \pm 2.26$ & $67.8 \pm 1.24^{*}$ & $67.5 \pm 0.07^{*}$ \\
\hline
\end{tabular}

Results are expressed as mean \pm SEM, the superscript $\left(^{*}\right)$ means

significant difference with respect to the control at $\mathrm{p}<0.05$ (ANOVA).

\subsection{Effects on Malondialdehyde and Superoxide Dismutase}

Treatment with SMX/TMP produced significant $(\mathrm{p}<0.05)$ time dependent increase in MDA level to $41.0 \pm 2.17$ and $42.5 \pm 1.36$ in week 6 and 8 respectively when compared with the control. Animals exposed to $\mathrm{LPV} / \mathrm{r}$ also showed significant $(\mathrm{p}<0.05)$ increase in MDA level in week 6 and 8 with respect to the control. When $(\mathrm{SMX} / \mathrm{TMP}+\mathrm{LPV} / \mathrm{r})$ were co administered, significant $(\mathrm{p}<0.05)$ increase in MDA level to $67.8 \pm 1.24$ and $67.5 \pm 0.07$ in week 6 and 8 respectively was noted when 
compared with the control. [Table 5] Exposure of animals to SMX/TMP produced an insignificant ( $>>0.05)$ decrease in SOD in week 2-8 with respect to the control. Animals treated with $\mathrm{LPV} / \mathrm{r}$ produced significant $(\mathrm{p}<0.05)$ decrease in SOD level in week 8 with respect to the control. The combine doses of these agents (SMX/TMP+LPV/r) significantly $(p<0.05)$ decreased SOD levels in week 8 with respect to the control [Table 6].

Table 6. Effect of lopinavir/ritonavir, sulfamethoxazole/ trimethoprim and co-administered lopinavir/ritonavir, + sulfamethoxazole/trimethoprim on liver SOD (units/mg protein) in rats

\begin{tabular}{|lcccc|}
\hline Dose mg/kg & Week2 & Week4 & Week 6 & Week 8 \\
\hline Control & $25.5 \pm 1.02$ & $27.5 \pm 0.23$ & $2.95 \pm 1.71$ & $30.5 \pm 3.17$ \\
\hline $\begin{array}{l}\text { SMX/TMP } \\
(\mathbf{1 1 . 2 / 2 . 3 )}\end{array}$ & $29.3 \pm 0.15$ & $29.3 \pm 2.17$ & $27.0 \pm 2.07$ & $28.5 \pm 2.26$ \\
\hline $\begin{array}{l}\text { LPV/r } \\
(\mathbf{1 1 . 4 / 2 . 9 )}\end{array}$ & $28.0 \pm 1.26$ & $27.8 \pm 2.13$ & $25.721 .04^{*}$ & $17.5 \pm 0.16^{*}$ \\
\hline SMX/TMP+LPV/r & $26.4 \pm 1.04$ & $24.5 \pm 2.16$ & $24.4 \pm 2.16$ & $16.5 \pm 0.07^{*}$ \\
\hline
\end{tabular}

Results are expressed as mean \pm SEM, the superscript (*) means significant difference with respect to the control at $\mathrm{p}<0.05$ (ANOVA).

\subsection{Effect on Histopatology of the Liver}

The histopathological effects of SMX, LPV/r and combined doses of SMX/TMP+LPV/r on the liver are shown in Figure 1- 4. The liver of animals in control group treated with $1 \%$ ethanol shows normal histological structure of the central vein, portal area and normal platelets of hepatocytes as shown in Figure 1. Liver of animals treated with LPV/r $(11.4 / 2.9 \mathrm{mg} / \mathrm{kg})$ for 8 weeks shows fairly preserved lobular architecture with normal plates of hepatocytes. There is vascular congestion with scanty inflammatory cells infiltration in the parenchyma [Figure 2].

Evaluation of the liver of animals treated with (11.2/2.3 $\mathrm{mg} / \mathrm{kg}$ ) of SMX/TMP for 8 weeks shows fairly preserved lobular architecture with normal plates of hepatocytes. Vivid observation reveals vascular congestion and scanty inflammatory cells infiltration in the parenchyma. [Figure 3] Liver of animals' co administered with SMX/TMP + $\mathrm{LVP} / \mathrm{r}$ shows more vascular congestion and high inflammatory cells infiltration in the parenchyma [Figure 4].

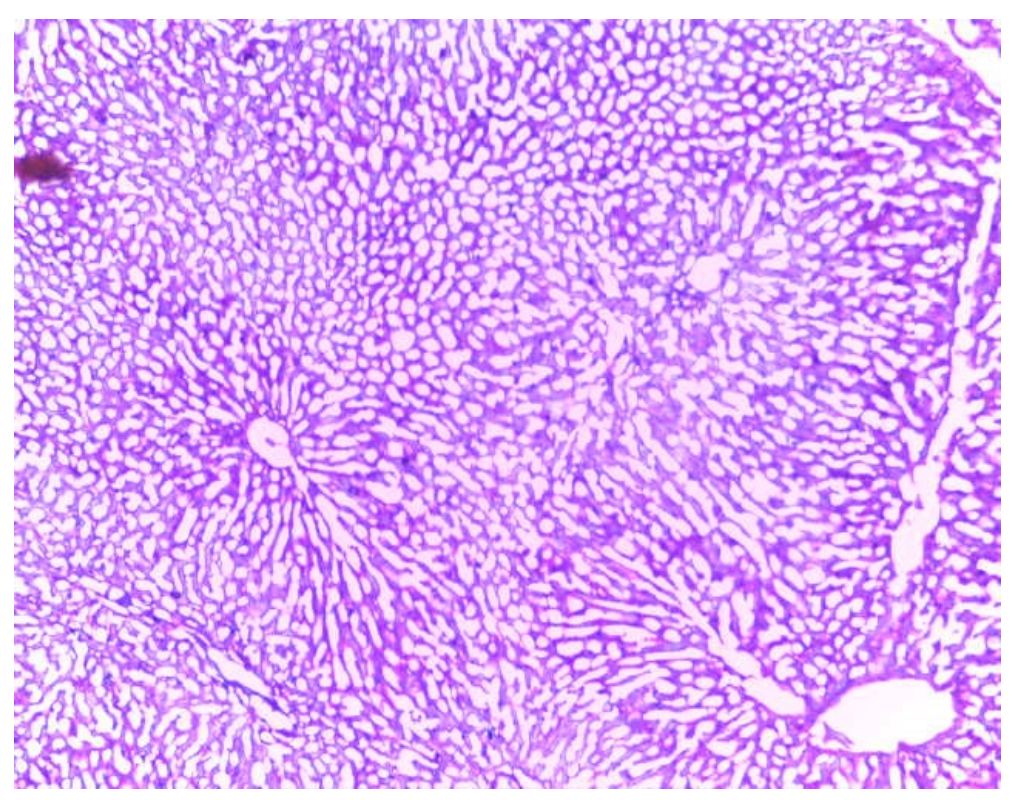

Figure 1. Photomicrograph of the H\&E stained sections of liver from control rat treated with $1 \%$ ethanol showing normal histological structure of the central vein, portal area and normal platelets of hepatocytes. (Mag. x 400)

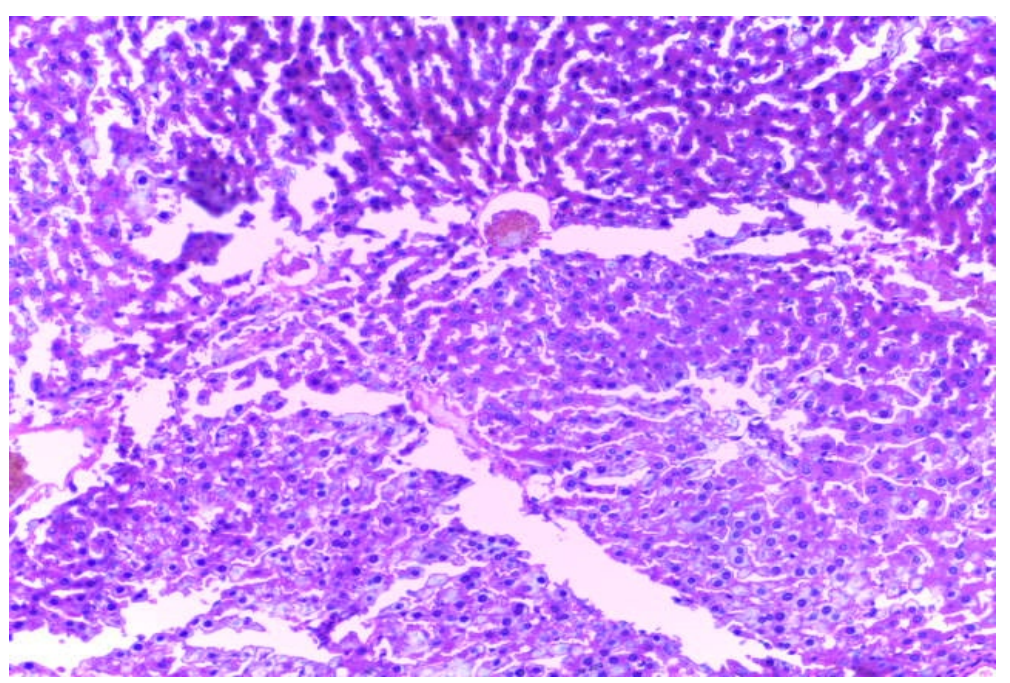

Figure 2. Photomicrograph of the H\&E stained sections of the liver of rats treated with LPV/r (11.4/2.9mg/kg) for 8 weeks showing fairly preserved lobular architecture with normal plates of hepatocytes. There is vascular congestion with scanty inflammatory cells infiltration in the parenchyma. (Mag. x 400) 


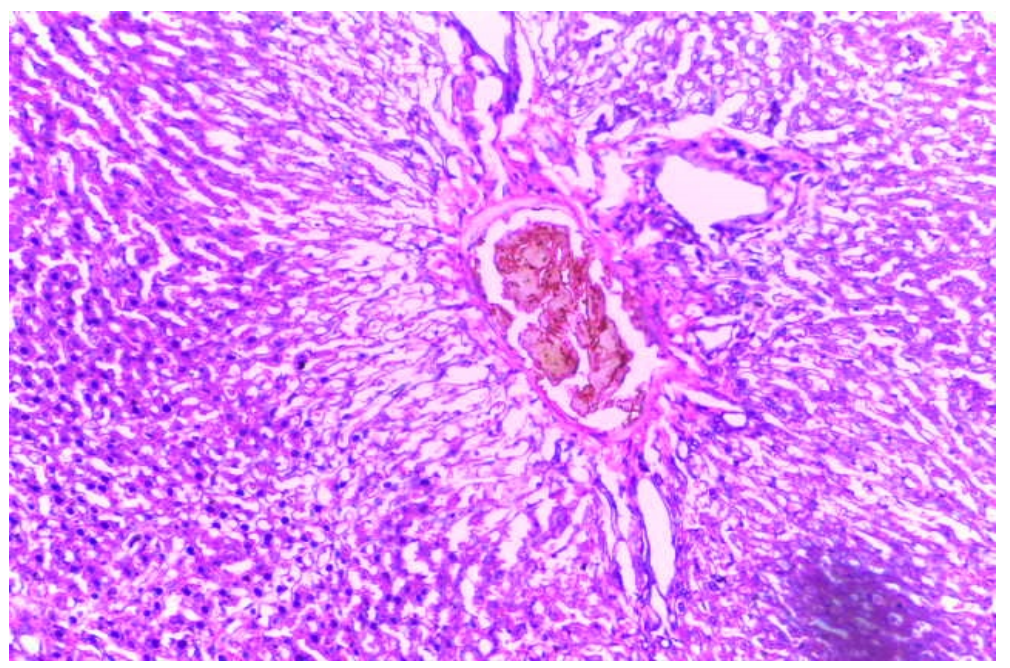

Figure 3. Photomicrograph of the H\&E stained sections of the liver of rats treated with SMX/TMP (11.2/2.3 mg/kg) for 8 weeks showing fairly preserved lobular architecture with normal plates of hepatocytes. There is vascular congestion with scanty inflammatory cells infiltration in the parenchyma. (Mag. x 400)

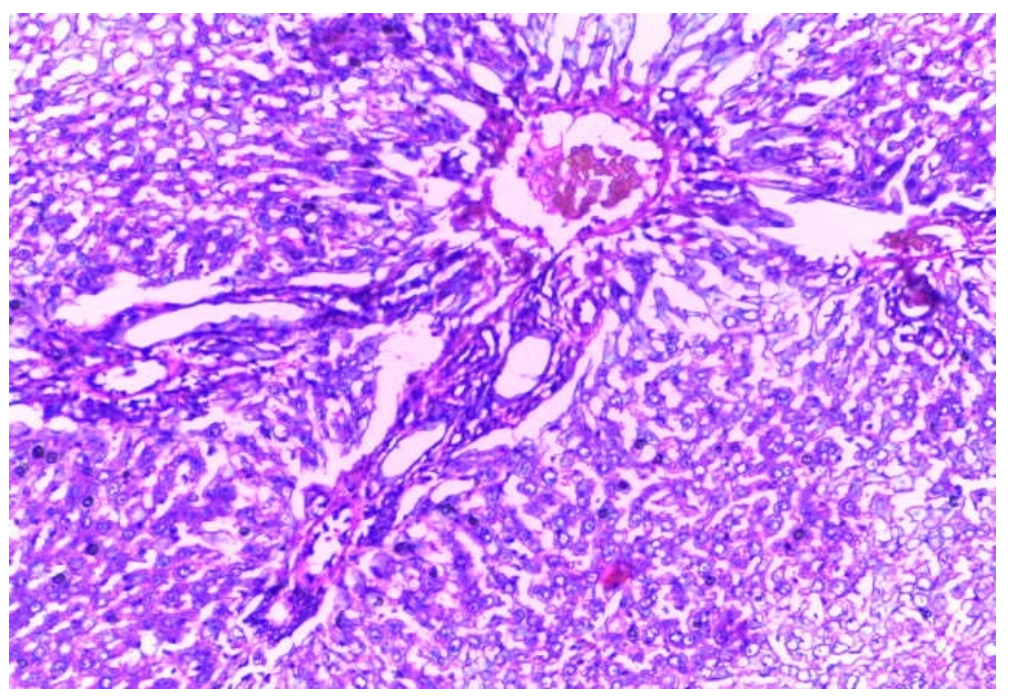

Figure 4. Photomicrograph of the H\&E stained sections of liver of rat treated with combined doses of SMX/TMP and LPV/r for 8 weeks showing fairly preserved lobular architecture with normal plates of hepatocytes. There is vascular congestion and inflammatory cells infiltration in the parenchyma. (Mag. x 400)

\section{Dicussion}

Lopinavir boosted with ritonavir is a protease inhibitor used in combination with other antiretroviral drugs in the management of patients with HIV/AIDS [19]. SMX/TMP is use for prophylaxis and in the treatment of pneumocystic carinii pneumonia and other opportunistic infections in HIV/AIDS patients [20]. Due to HIV/AIDS associated co morbidity and co infections the concurrent use of antiretroviral agents and antibacterial agents is highly pronounced [21]. This may produce synergistic adverse events on body organs especially those involved in drug metabolism and excretion. This work evaluates the toxicological effects of co administered SMX/TMP and $\mathrm{LPV} / \mathrm{r}$ on serum ALT, AST and ALP of albino rats. Liver SOD, MDA and histopathological changes were also evaluated.

In this work, observed increase in levels of ALT, AST and ALP in animals treated with SMX/TMP agrees with reported observations by some scholars [22,23,24]. Elevation in the levels of ALT, AST, and ALP in animals treated with $\mathrm{LPV} / \mathrm{r}$ is consistent with some reported observations [25,26,27]. Insignificant increase in biomarkers of hepatic function observed in animals treated with combine dose of these agents (SMX/TMP + LVP/r) shows lack of toxicological synergy. Reports have shown that elevations in serum levels of ALT, AST and ALP as seen in this study is a marker of hepatotoxicity [28,29]. The increase in serum levels of hepatic markers observed in this study could be attributed to liver injury, because these enzymes are place in cytoplasmic area of the cell and are released into circulation in case of cellular damage [30,31].

Increase in MDA observed in LPV/r treated animals is consistent with reported observation by some scholars [32]. Gupta et al., 2013 also reported increased in MDA level in SMX/TMP treated animals which is in agreement with observation in this study [33]. Also insignificant increase observed when these agents were co administered could be attributed to lack of synergistic toxicological action by these agents. Decrease in SOD noted in this work agrees with the work of Reyskens et al. 2013 who reported impairments in SOD level in rats treated with lopinavir/ritonavir for 8 weeks [34]. Increased MDA and decrease in SOD as observed in this study is an important indicator of lipid per oxidation and induced oxidative 
stress which could be attributed to free radical generation by these agents [35,36,37].

SMX/TMP associated hepatotoxicity is said to be a hypersensitivity reaction which could be triggered by three distinct processes: production of reactive metabolites, reactive oxygen species processing, and binding of reactive metabolites to proteins/DNA, resulting in inflammation, cell damage, neo-antigen formation, and immune response [38]. This is supported by observed increase in malondialdehyde level and decrease in SOD level in this work.

Previous studies suggested that HIV PI-induced endoplasmic reticulum stress response and subsequent activation of unfolded protein response represent important cellular signaling mechanisms of HIV PI- induced metabolic syndromes and hepatotoxicity [39,40,41]. Endoplasmic reticulum stress has been associated with the production of reactive oxygen species which can cause increase in MDA level and decrease in SOD level as observe in this study

The vascular congestions and inflammatory cells infiltration of the parenchyma observed in this study are degenerative changes which could lead to apoptotic cell death that can be characterized by series of morphological and biochemical changes [42,43]. Apoptotic cell death can be triggered in two path ways: by toxic chemicals or injury leading to damage of DNA, other important cellular targets, and activation or inactivation of receptors by growth-regulating signal factors in the organism [44]. This can be correlated with reported SMX/TMP and antiretroviral drugs induced DNA damage $[45,46]$.

\section{Conclusion}

In this study concurrent treatment with SMX/TMP + $\mathrm{LPV} / \mathrm{r}$ produced no synergistic hepatotoxicity, hence these agents can be use concurrently in HIV/AIDS associated co infection and co morbidity.

\section{References}

[1] UNAIDS. Report on the AIDS Epidemic 2006. Joint United Nations Programme on HIV/AIDS. Geneva, Switzerland. 2006.

[2] Global Report : UNAIDS reports on Global AIDS epidemic 2013.

[3] Palella FJ, K. M. Delaney A. C. Moorman et al. Declining morbidity and mortality among patients with advanced human immunodeficiency virus infection. HIV Outpatient Study Investigators. N Engl J Med., 338: 853-860. 1998.

[4] Chandwani A. and Shuter J. Lopinavir/ritonavir in the treatment of HIV-1 infection: a review. Ther Clin Risk Manag. 4; 5: 1023-1033.

[5] Snipes, C J.Trimethoprim-sulfamethoxazole: A Review of Use in Children Pediatric Pharmacotherapy A Monthly Newsletter for Health Care Professionals Children's Medical Center at the University of Virginia, 1998.

[6] Vilar F, S. Khoo, T. TWalley. The management of Pneumocystis carinii pneumonia. Br J Clin Pharmacol.;47 (6): 605-9, 1999.

[7] Hazin R, T. I Aburajab Tamimi, J. Y Abuzetun, N. N Zien, Recognizing and Treating Cutaneous Signs of Liver Disease. Cleve Clin J Med 76; (10)599-606. 2009.

[8] Olurishe T. O, H. O. Kwanashie, J. Anuka, H. Muktar, M. Bisalla 2011.. Histopathological effects of sub-chronic lamivudineartesunate co-administration on the liver of diseased adult Wistar rats. North Am J Med Sci., 3: 325-8. 2011

[9] Kielhofner, M. A. 1990. Trimethoprim- Sulfamethoxazole: Pharmacokinetics, Clinical Uses, and Adverse Reactions. Tex Heart Inst J., 17(2): 86-93. 1990.

[10] Hull M. W, M. Harris, V. Lima, et al, Lopinavir/ritonavir pharmacokinetics in a substitution of high-dose soft-gelatin capsule to tablet formulation. J Clin Pharmacol., 49: 155-61, 2009.
[11] Reyskens KMSE, T. L. Fisher, J. C. Schisler, O'Connor WG, Rogers AB, et al.. Maladaptive Effects of HIV Protease Inhibitors (Lopinavir/ Ritonavir), PLOS ONE 8(9): e73347. 2013.

[12] Nathiya. S, and A. Nandhini. Evaluation of antioxidant effect of Salacia oblonga against aluminum chloride induced visceral toxicity in albino rats Int J Basic Clin Pharmacol. 3(2): 315-319. 2014.

[13] Draper H. H, M. Hadley. Malondialdehyde determination as index of lipid peroxidation. Methods Enzymol., 186: 421-431.1990.

[14] Beauchamp C, Fridovic I.. Superoxide dismutase: improved assays and an assay applicable to acryl amide gels. Anal. Biochem. 44: 276-287. 1971.

[15] Reitman, S., and S. Frank. Transaminases. American Journal of Clinical pathology: 28:56.

[16] King, E. J.and P. R. N King, 1954.Estimation of plasma phosphatase by determination of hydrolyzed phenol with aminoantipyrene. J. Chem. Path. 7: 322-326.1957.

[17] Malloy, E. K. Evelyn. Colorimetric method for the determination of serum oxaloaceti and glutamic pyruvate transaminase., Am. $J$. Clin. Pathol. 28: 56-63. 1932.

[18] Drury, R.A.B., E.A. Wallington and R. Cameron, 1967. Carleton's Histological Techniques. 4th Edn., Oxford University Press, NY. USA, pp: 279-280.

[19] Oldfield V, G. L. Plosker, Lopinavir/ritonavir: a review of its use in the management of HIV infection. Drugs. 66(9): 1275-99. 2006.

[20] WHO (2013). World Health Statistics 2013. World Health Organization, Geneva, Switzerland. Available at: http://www.who.int/gho/publications/world_health.

[21] WHO (2006). Towards Universal Access: Scaling up Priority HIV/ AIDS Interventions in the Health Sector. Progress Report. World Health Organization Geneva, Switzerland.

[22] Altraif I, L. Lilly, I. Wanless, J. Heathcote. Cholestatic liver disease with ductopenia (vanishing bile duct syndrome) after administration of clindamycin and trimethoprimsulfamethoxazole. Am J Gastroenterol., 89: 1230-4.1994

[23] Marius J M, J. Ruiz, A. Axiotis. 2000. Acute fulminant hepatic failure in a woman treated with phenytoin and trimethoprimsulfamethoxazole. Arch Pathol Lab Med., 124: 180003. 2000

[24] Zaman F, Ye G, Abreo K. D, Latif S, Zibari GB. Successful orthotopic liver transplantation after trimethoprimsulfamethoxazole associated fulminant liver failure. Clin Transplant. 17: 461-4. 2003.

[25] Cameron, D. W, S. Becker, M. S. King, B. Da Silva, C. Klein, D. Tokimoto, C. Foit, D. Calhoun et al., Exploratory study comparing the metabolic toxicities of a lopinavir/ ritonavir plus saquinavir dual protease inhibitor regimen versus a lopinavir/ritonavir plus zidovudine/lamivudine nucleoside regimen Jour of Antimicrob Chemother 59, 957-963. 2007.

[26] Gonzales de Requena D, M. Nunez, 1. Jimenez-Nacher et al. Short communication: liver toxicity of lopinavir/ritonavir-containing regimens in HIV-infected patients with or without hepatitis C coinfection. AIDS Res Hum Retroviruses; 20: 698-700, 2004.

[27] Seminari E, G. Gentilini L. Galli et al. Higher plasma lopinavir concentrations are associated with a moderate rise in cholestasis markers in HIV-infected patients. J AntimicrobChemother; 56: 790-2. 2005.

[28] Mercer D. W, and T.S. Talamo. The role of biochemical markers in the management of cancer, In, Clinical Studies in Medical Biochemistry: Glew RH, Peters SP (ed). Oxford University Press. 25-34.1987.

[29] Muragesh K. S, V.C. Yeliogor, B. C. Maiti, T. K. Maity. Hepatoprotective and Antioxidenat role of Berberis tinetoria Lesch leaves on Paracetamol-induced hepatic damage in rats. Iranian. $J$. Pharmacol. 22: 107-109. 2005.

[30] Recknagel R. O, J. E. AGlende, J. A. Dolack, Mechanisms of carbon tetrachloride toxicity. Pharmacol Ther 43:139-154, 1989.

[31] Adaramoye, OA, Adesanoye OA, Odewumi OM,. Studies on the toxicological effect of nevirapine, an antiretroviral drug, on the liver, kidney and testis of male Wistar rats. Source: A. Human \& Experimental Toxicology. 3 (7) 676-685.2013.

[32] Adaramoye O. A, O. M Adewumi, O. A Adesanoye., O. Faokunla, E. O Farombi. Effect of tenofovir, an antiretroviral drug, on hepatic and renal functional indices of Wistar rats: protective role of vitamin E: Jourl of Basic and Clini Physio and Pharmacol 23, ( 2) 69-75, 2012

[33] Gupta, R and Anwar F, Khosa, R L, The Effect of Sulfamethoxazole and Selenium on Antioxidant Defense System 
in the Blood of Rats Treated With DEN. Jour of Pharm and Biol Sci, 8, (6) 29-37. 2013.

[34] Reyskens KMSE, T. L. Fisher, J. C. Schisler, O’Connor WG, Rogers AB. Cardio-Metabolic Effects of HIV Protease Inhibitors (Lopinavir/ Ritonavir), PLoS ONE 8(9): e73347. 2013.

[35] Ogbuehi, I, E, Adikwu and D. Oputiri. Effect of Acalypha wilkesiana MuellArg Leaf Extract on the Oxidative Indices, Liver Enzymes and Liver Integrity of Rats Infected with Plasmodium berghei Brit Jour of Pharm and Tox,5(2): 68-74, 2014.

[36] Conklin BS, Fu W, Lin PH, Lumsden AB, Yao, Q, Chen C,HIV protease inhibitor ritonavir decreases endothelium-dependent vasorelaxation and increases superoxide in porcine arteries. Cardiovascular Research 63; 168-175. 2014.

[37] Jiang B, Hebert VY, Li Y, Mathis JM, Alexander JS, et al. HIV antiretroviral drug combination induces endothelial mitochondrial dysfunction and reactive oxygen species production, but not apoptosis. Toxicol Appl Pharmacol, 224: 60-71. 2007,

[38] Wang, D. A. Curtis, A. C. Papp, S.L Koletar and M. F. Para. Polymorphism in glutamate cysteine ligase catalytic subunit (GCLC) is associated with sulfamethoxazole - induced hypersensitivity in Hiv/AIDS patients. BMC Medical Genomics 5: 32: 2-9. 2012.

[39] Zhou H, E. C. Gurley, S. Jarujaron, H. Ding, Y. Fang, Xu Z, et al HIV protease inhibitors activate the unfolded protein response and disrupt lipid metabolism in primary hepatocytes. Am J Physiol Gastrointest Liver Physiol., 291:1071-1080. 2006.
[40] Scull CM, I. Tabas. Mechanisms of ER stress-induced apoptosis in atherosclerosis. Arterioscler Thromb Vasc Biol., 31: 2792-2797. 2011.

[41] Ozcan L, and I. Tabas, Role of endoplasmic reticulum stress in metabolic disease and other disorders. Аnnu Rev Med, 63: 317328.2012.

[42] Shen, H.M., J. Dai, S.E. Chia, A. Lim and C.N. Ong,. Detection of apoptotic alterations in sperm in subfertile patients and their correlations with sperm quality. Hum. Reprod., 17: 12661273.2002

[43] Grunewald, S., U. Paasch, T.M. Said, R.K. Sharma, H.J. Glander and A. Agarwal,. Caspase activation in human spermatozoa in response to physiological and pathological stimuli. Fertil Steril, 83 (1): 1106-1112. 2005.

[44] Schulte-Hermann, R., W. Bursch, B. Marian and B. Grasl-Kraupp. Active cell death (apoptosis) and cellular proliferation as indicators of exposure to carcinogens. IARC Scientific Publications (Lyon), 146: 273-285. 1999.

[45] Patel R. B, P. G. Welling. Clinical pharmacokinetics of cotrimoxazole (trimethoprim-sulphamethoxazole). Clin Pharmacokinet 5: 405-23. 1980.

[46] Zhong, D, Lu, X, Conklin, BS, Lin, PH. Lumsden, AB, Yao Q. HIV Protease Inhibitor Ritonavir Induces Cytotoxicity of Human Endothelial Cells Arterioscler Thromb Vasc Biol.;22: 1560-1566, 2002. 